\title{
Seismic vulnerability and property losses to the Portuguese industrial steel building stock
}

\author{
Miguel Araújo ${ }^{1}$, José Miguel Castro² and Mário Marques ${ }^{3}$ \\ Faculty of Engineering, University of Porto, Porto, Portugal (1'maraujo@fe.up.pt, \\ 2miguel.castro@fe.up.pt, ${ }^{3}$ mariom@fe.up.pt)
}

\begin{abstract}
Industry plays a key role in the economy of a country, people welfare and socioeconomic resilience to natural disasters. Earthquakes are known to have damaging impacts on industrial property and activity, oftentimes resulting in costly structural and non-structural losses to industrial buildings, business closure, production failure and job losses. Notwithstanding this fact, the industrial building stock has been continuously excluded from seismic risk models developed for Portugal as it is usually assumed that industrial buildings are expected to withstand strong earthquakes due to their lightweight and design governed by wind loads. The aim of this paper is thus to give a first contribution to the assessment of the seismic vulnerability and property losses of the existing Portuguese industrial steel building stock. Both losses to structural and non-structural components and industry-specific contents, such as production equipment and machinery, are taken into account. The expected direct industrial property losses for a probability of exceedance of $10 \%$ in 50 years for mainland Portugal are herein estimated.
\end{abstract}

Subject Headings. Seismic Risk, Natural Disasters

Author Keywords. Property Losses, Industrial Buildings, Steel Structures

\section{Introduction}

Portugal is the westernmost country of Europe, being located in a seismic-prone region just next to the border of the Eurasian plate. A recent comprehensive study conducted by Silva et al. (2015) evidenced some alarming scenarios, wherein a future event with a return period of 475 years, i.e., probability of exceedance of $10 \%$ in 50 years, was shown to produce mean economic losses to the current residential building stock of approximately $30 \%$ of the national GDP, without accounting for non-structural components and building contents. This increasing awareness has been recently strengthened by a Parliament Resolution on seismic risk reduction and new legislation on Critical Infrastructure Protection (Lopes et al., 2012). However, current existing seismic risk models are mainly based on the physical vulnerability of the existing residential building stock, integrating, or not, social vulnerability models (Burton and Silva, 2015). Still none has yet been developed incorporating any industrial vulnerability model, although some of the most vulnerable areas, such as the Lisbon and Tagus Valley region, are fairly industrialized and responsible for a great portion of the national GDP. Despite being generally assumed that industrial buildings are expected to endure strong earthquakes due to their lightweight and structural design governed by wind loads, recent seismic events have induced significant levels of damage to structural and, more importantly, to non-structural components (Clifton et al., 2011; Midorikawa et al., 2012). Whereas many pre-cast concrete buildings were seen to exhibit brittle failure of joints between the roof beam and the columns, steel buildings oftentimes exhibited severe brace buckling, net-section fracture, distortion and fracture of the gusset plates and pull-out of column base plates due 
to fracture of anchor bolts. Dropping of ceilings and exterior walls and breakage of windows were the most commonly observed non-structural damages, being the falling debris one of the main reasons for equipment damage and loss (Krausmann et al., 2010).

This paper hence aims at estimating the direct industrial property losses to the current industrial steel building stock existing in Mainland Portugal. The most common sources of structural damage identified in post-earthquake reconnaissance campaigns, such as failure of column base connections and out-of-plane buckling and fracture of bracing systems, were modelled and assessed in the derivation of a novel vulnerability model for industrial steel buildings. To account for the randomness in the geometrical and material parameters of the existing industrial steel building stock, more than 200 blueprints of existing industrial steel buildings collected from Portuguese design offices and steelworks companies were inspected and a set of probability density functions was fitted to the collected data to further support the random generation of a wide range of synthetic industrial steel buildings using a multivariate Latin Hypercube method sampling technique. Finally, the direct industrial property losses for a probability of exceedance of $10 \%$ in 50 years were quantified at a national scale for Mainland Portugal using a web-based platform for seismic loss estimation recently developed at the University of Porto under the FCT-nationally founded PRISE project, which relies on the open-source OpenQuake engine (Silva et al., 2014).

\section{Seismic vulnerability of the Portuguese industrial steel building stock}

When data regarding post-earthquake damage levels are not available and no information exists with respect to the expected seismic vulnerability of different building categories, analytical methodologies have to be employed both to predict the vulnerability of the existing building stock and to group it into different taxonomies (Silva et al., 2015b). These analytical methodologies involve the generation of a sufficient number of synthetic buildings representative of the existing building stock that should be afterwards seismically assessed to increasing levels of ground motion intensities so as to derive their corresponding fragility and vulnerability functions. The probabilistic modelling of such a wide range of synthetic buildings is made by assuming that the variation in the material properties and geometrical characteristics within a building category can be represented as a random variability, although, as noted by Crowley et al. (2005), this variation is an epistemic uncertainty as its exact distribution could be determine by detailed inspection of all buildings. Therefore, similarly to the work of Silva et al. (2015b), Crowley et al. (2004) and Bal et al. (2008), probabilistic distributions were fitted to data of a set of geometric parameters of industrial buildings (with years of construction ranging from 1995 to 2014) obtained from the inspection of more than 200 blueprint drawings from design offices and steelworks companies. These distributions were posteriorly employed in the random generation of samples of buildings using simulation techniques, e.g. Monte Carlo Sampling Method or Latin Hypercube Sampling Method (Moore et al., 2009). The statistical parameters of the probabilistic distributions were derived using the maximum likelihood approach and the goodness-of-fit of each distribution was evaluated using the Chi-square test for significance levels of $1 \%, 5 \%$ and $10 \%$. If any distribution satisfied the latter condition, the Kolmogorov-Smirnov test was alternatively applied for the same significance levels and the probability plots were visually inspected, being the best-fit assessed on the basis of a parametric bootstrap simulation on the correlation coefficient using 1000 samples.

After the random generation of each industrial building, the cross-section sizes of all structural members were designed in accordance with the Portuguese regulations that were in force 
over the past 50 years (REAE, 1965; 1986; CEN, 2005), so as to generate synthetic buildings that more accurately represent the lateral stiffness and strength of the existing Portuguese industrial building stock. Since most Portuguese practitioners have been simply designing industrial buildings to laterally withstand wind loads, particular attention was paid to past regulation that specifically addresses this issue (RSEP, 1961; RSA, 1983; CEN, 2010).

\subsection{Characterization of the Portuguese existing industrial steel building stock}

A report recently elaborated within a European founded research project, the Precasteel project (RFCS, 2013), indicates that practically $60 \%$ of the Portuguese existing industrial building stock is made of steel, $30 \%$ refers to reinforced concrete structures and $10 \%$ uses other structural solutions. Despite the high vulnerability exhibited by the Italian pre-fabricated $\mathrm{RC}$ industrial building stock during the 2012 Emilia-Romagna earthquake, which resulted in substantial building collapses, mostly due to the brittle failure of the pre-fabricated RC girders and columns joints (Casotto et al., 2015), this type of building typology will be neglected as a result of its lower level of exposure in comparison to the industrial steel building stock. Regarding the latter, it was observed from the conducted survey that $30 \%$ of the as-built Portuguese steel buildings stock adopts lattice structures and that $70 \%$ was built with portal frame structures. This distribution of building typologies is in complete agreement with that indicated by the Precasteel project (RFCS, 2013), therefore validating the information collected in the conducted survey and following statistical analyses. In order to streamline the presentation and interpretation of the collected data, namely the fitting of the probability distribution functions to the buildings' geometrical parameters that will support the random generation of a wide range of synthetic industrial steel buildings, a brief discussion on the main features of the as-built Portuguese industrial building stock is presented below.

- Dependence on the type of industrial activity: No statistical evidence was found that supports the dependency of the structural typology (e.g., portal frame or lattice structures) on the industrial activity. This could be previously anticipated since lattice buildings typically have greater dimensions, when comparing to portal frame buildings, and could tend to be associated to industrial activities, rather than warehousing. By disaggregating the collected information, such a dependency was not found to exist, with $57 \%$ of lattice buildings and $45 \%$ of portal frame buildings being associated to light industry, respectively, while the remaining $43 \%$ and $55 \%$ were seen to be associated to warehousing. These percentages are, in fact, in accordance with the Precasteel project (RFCS, 2013), which refers that $45 \%$ of the Portuguese as-built industrial building stock respects to light industry, $45 \%$ to warehousing and only $10 \%$ to heavy industry.

- Structural Steel Class: Most buildings inspected (93\%) were built with a structural steel of class S275. A small minority (7\%) was built with a structural steel of class S235.

- Number and distance between consecutive frames: On the basis of logistic regression analysis (Moore et al., 2009), statistical dependency was found to exist between the number of frames ( $p$-value $=0.01)$, the distance of frames ( $p$-value $=0.07$ ) and the building typology. Whereas lattice structural solutions are mainly adopted in longer buildings, i.e. with more than 15 frames and a spacing between them that can reach $18 \mathrm{~m}$, portal frame solutions are usually used in shorter buildings, with 3 to 15 frames and a spacing between them lesser than $8 \mathrm{~m}$. With respect to the fitting of the probability distribution functions, it was found that the number and distance between consecutive frames of lattice buildings follow a lognormal distribution, with mean and coefficient of variation shown in Figure 1, satisfying the Chi-square and Kolmogorov-Smirnov 
goodness-of-fit tests for a significance level of $1 \%$. In turn, regarding the portal frame buildings, the number of frames was found to follow a normal distribution and the distance between consecutive frames follow a lognormal distributions, Figure 2, passing the Kolmogorov-Smirnov test with a significance level of $1 \%$. According to discrete information provided by the Precasteel project (RFCS, 2013), 65\% of the Portuguese industrial buildings have up to 11 frames and $90 \%$ have a spacing between $5 \mathrm{~m}$ to $7 \mathrm{~m}$. Confronting these values with those obtained from the fitted probability distribution functions, i.e. $78 \%$ of the buildings have up to 11 frames and $84 \%$ have a spacing between $5 \mathrm{~m}$ to $7 \mathrm{~m}$, one may conclude that they are in somehow good agreement.
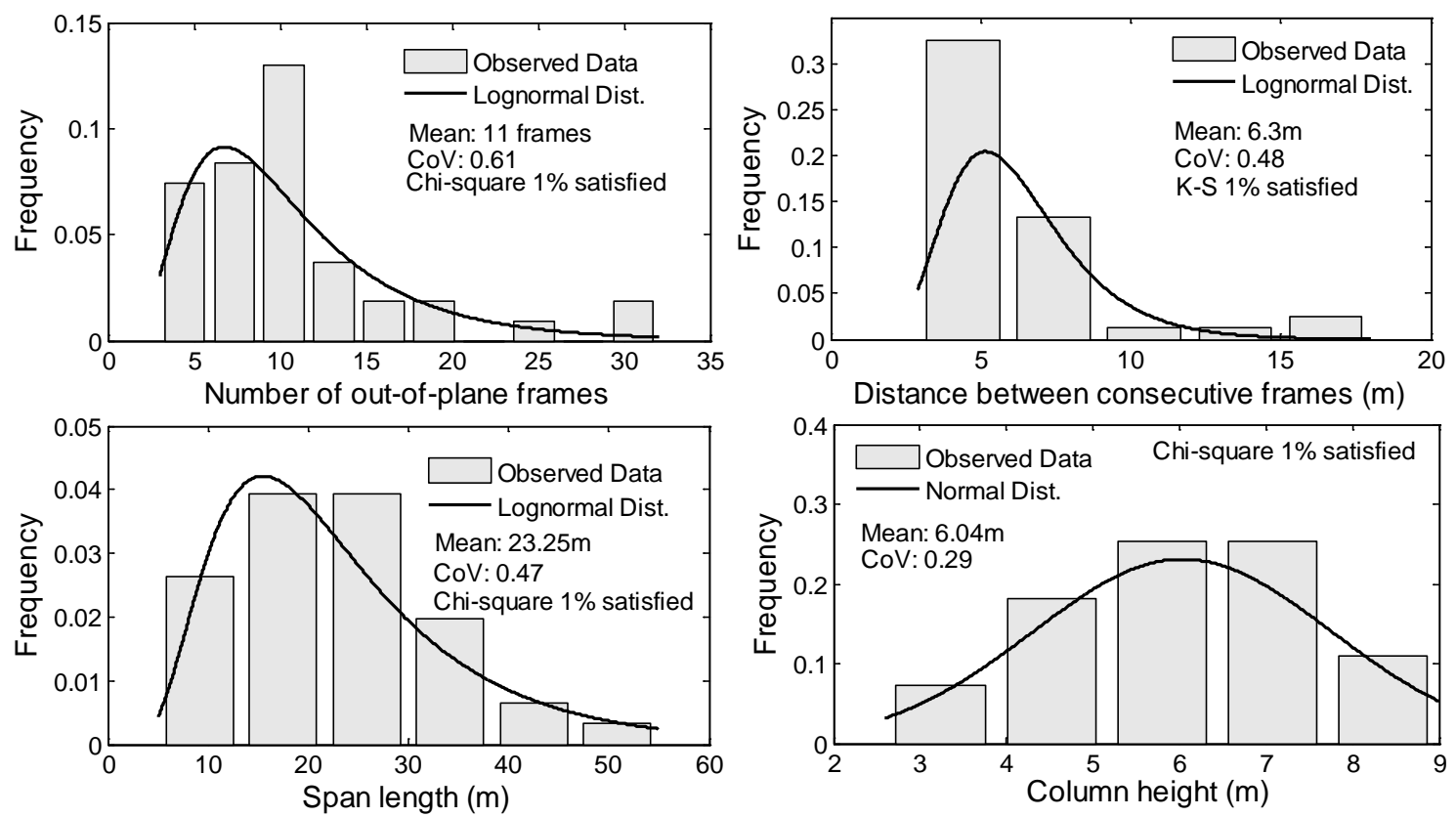

Figure 1: Fitting of probability distributions to the geometrical characteristics of industrial lattice buildings

- Number and length of spans: The Portuguese as-built industrial steel building stock typically displays a single span (65\%), a small percentage displays two (17\%) or three (11\%) spans and a minority displays more than four spans (7\%). It should be noted, however, that although industrial steel buildings with multiple spans refer to a small share of the existing industrial building stock, this building typology can be more susceptible to seismic actions as a result of the common removal of internal columns for space optimization and accommodation of the production layout. Similarly to previous geometric parameters, it was found that the length of spans follows a lognormal distribution, satisfying the Chi-square test for a significance level of $1 \%$, as depicted in Figure 1 and Figure 2. On average, the span length was seen to be around $23 \mathrm{~m}$ in the case of lattice structures and around $20 \mathrm{~m}$ in the case of portal frame structures. According to the Precasteel project (RFCS, 2013), 15\% of Portuguese buildings have spans with less than $20 \mathrm{~m}, 50 \%$ have spans between $20 \mathrm{~m}$ to $25 \mathrm{~m}, 25 \%$ have spans between $25 \mathrm{~m}$ and $30 \mathrm{~m}$ and $10 \%$ have spans with more than $30 \mathrm{~m}$. Confronting this percentages with those obtained using the probability distribution functions fitted for lattice structures, values of $16 \%, 56 \%, 24 \%$ and $4 \%$, were obtained, respectively, thus strongly supporting the collected data. Still, these values were seen to diverge from those obtained for portal frame structures, which are around $48 \%, 46 \%, 5.8 \%$ and $0.2 \%$, respectively, and reflect the lower span lengths exhibited by this building typology. 
Furthermore, by conducting correlation analyses between the span length and the remaining geometric parameters, a moderate and positive correlation, i.e. coefficient of correlation $\rho$ of 0.41 , between the span length and the number of frames was found to exist, which could be previously anticipated due to space implications and needs. At last, it should be referred that IPE cross-section profiles were seen to be typically adopted in portal frame structures (90\%) and that, on average, the portal frame girders exhibit a 70 slope that follows a lognormal distribution with the parameters presented in Figure 2. Current practices in Portugal consist on adopting hunched bolted column-to-girder connections with haunch lengths that vary from $10 \%$ to $20 \%$ of the span length.

- Type and height of columns: Generally speaking, it was seen that RC columns are usually adopted in lattice buildings ( $75 \%$ of cases) and that steel columns are characteristic of portal frame buildings (95\% of cases). IPE cross-section profiles are more frequently used in the latter case (75\%). Once again, on the basis of regressions logistic analysis, a statistical dependence between the height of columns and the number of floors was found to exist ( $p$-value $=0.02$ ). Nevertheless, since only $6 \%$ of the collected buildings has more than one floor, it was assumed that this building typology is not representative of the existing building stock. Furthermore, it was observed that the height of columns, for both lattice and portal frame structures, follow a lognormal distribution with parameters presented in Figure 1 and Figure 2, satisfying the Chi-square test for a significance level of $1 \%$.
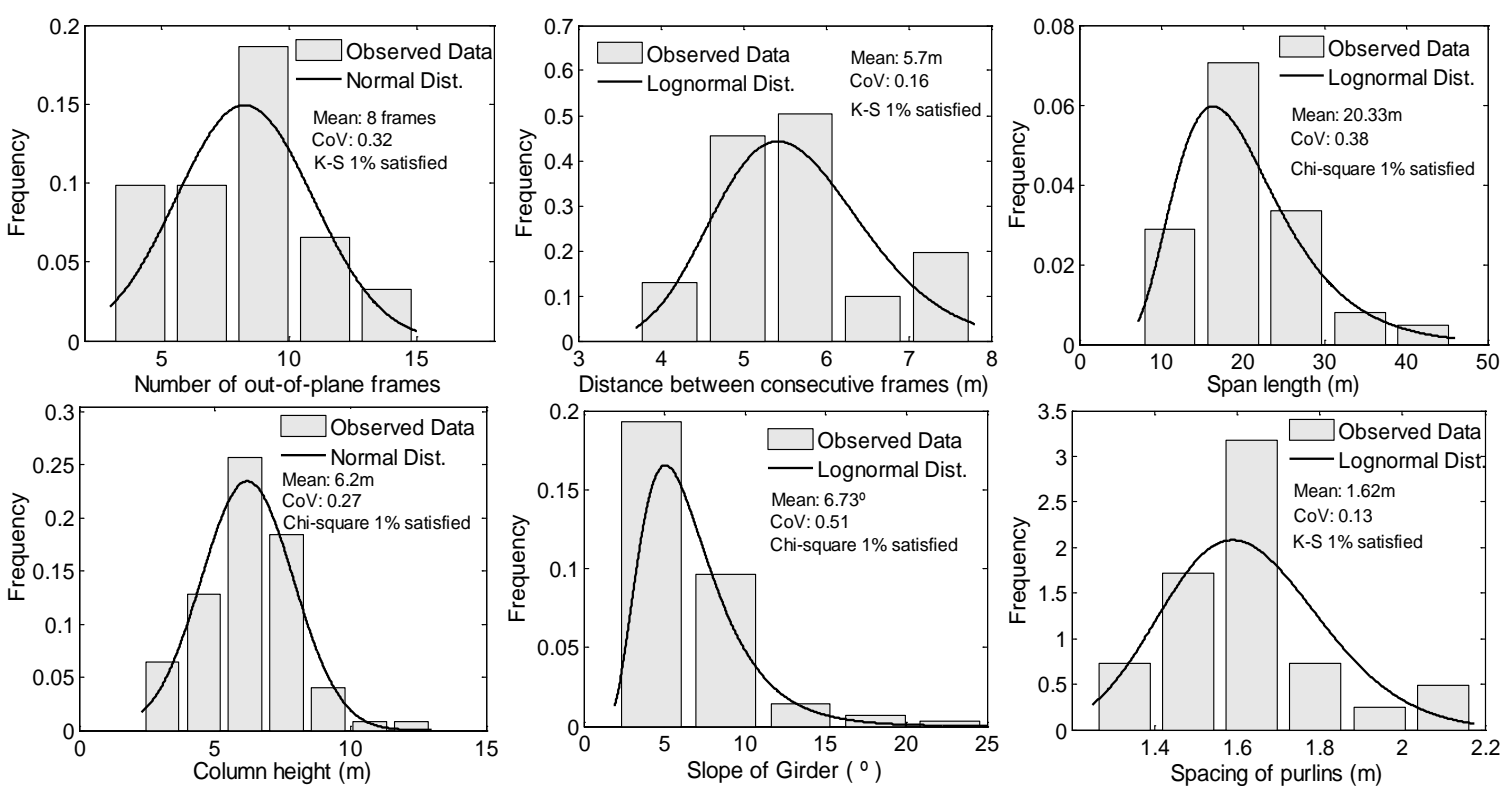

Figure 2: Fitting of probability distributions to the geometrical characteristics of industrial portal frame buildings

- Structural systems in the transverse and longitudinal directions: The collected information indicates that the Portuguese industrial steel building stock is typically characterized by unbraced moment-resisting frame systems in the in-plane transverse direction. This information is in agreement with that of the Precasteel project (RFCS, 2013), which refers that in-plan moment-resisting frames represent $90 \%$ of the Portuguese building stock and that only $10 \%$ is characterized by systems with concentric or eccentric braces. In turn, in the longitudinal out-of-plane direction, it was observed that $70 \%$ of portal frame buildings are braced, mostly with diagonal concentric braces, and that $74 \%$ of lattice buildings adopt common moment-resisting frame solutions. 
Again, on the basis of logistic regression analysis, statistical dependencies between the use of bracing system and the year of construction ( $p$-value $=0.03$ ) and between the use of bracing system and the height of columns ( $p$-value $=0.02$ ) were found to exist. These dependencies may be explained, on the one hand, by the fact that lattice structures have been more commonly adopted in the past, which, as already referred, are typically characterized by in-plane moment-resisting frames; and, on the other hand, by the fact that higher columns tend to be associated to unbearable flexural demands in the direction of the weak axes, thus requiring the use of bracing systems.

- Type of column base plate connections: Although it was not possibly to identify any tendency on the most common type of base plate connections adopted in Portugal, two major groups were defined: (i) exposed base plate connections with single rows of four bolts outside both flanges of the column cross-section, herein designated as SBPC connections. These connections typically have plates with $25 \mathrm{~mm}$ thickness and a high 1.7 times greater than the height of the column cross-section. M22 anchor bolts of 8.8 class with a length of $500 \mathrm{~mm}$, concrete footing of C20/25 class, 60MPa grouting with $35 \mathrm{~mm}$ thickness, S275 steel grades and welds with $8 \mathrm{~mm}$ are usually adopted; (ii) exposed base plate connections with single rows of two or three bolts at both sides of the web and inside the flanges of the column cross-section, designated as PBPC connections. In this case the base plate typically has a height equal to that of the column cross-section and M20 anchor bolts are adopted.

- Non-structural components: The disaggregation of the collected information allowed observing that $90 \%$ of the inspected buildings adopt sandwich panels on the roof and that the remaining $10 \%$ have roofs made of fibrocement. In turn, with regard to side claddings, whilst $7 \%$ of the inspected buildings have masonry walls, the remaining buildings use corrugated metal sheets (52\%) and sandwich panels (41\%). Moreover, it was additionally observed that the existing industrial building stock typically adopts cold-formed steel purlins (78\%), usually with Z cross-section profiles (54\%) and U or L cross-section profiles (24\%), having an average spacing between them of $1.62 \mathrm{~m}$. The latter was found to follow a lognormal distribution as depicted in Figure 2.

Since the use of overhead travelling cranes is mostly related to heavier industrial activities (RFCS, 2013), their influence will be neglected herein, although being recognized the importance of such components on the dynamic response of industrial buildings and the potential losses that their failure and falling down may cause to the contents below, as observed in previous earthquake events (Moat et al., 2000).

\subsection{Derivation of vulnerability curves}

To analytically derive vulnerability curves representative of the Portuguese industrial steel building stock, a collection of 300 synthetic buildings was generated and subjected to a suit of twenty ground motion records selected and scaled using the Generalized Conditional Intensity Measure approach proposed by Bradley (2010). The geometric mean of the $5 \%$ damping spectral accelerations of the two horizontal $x$ and $y$ components at the transverse fundamental period of vibration $T_{x}, S_{a, x}\left(T_{x}, 5 \%\right)$ and $S_{a, y}\left(T_{x}, 5 \%\right)$, respectively, was set as main intensity measure for record selection and scaling. To keep the computational effort at a reasonable level, the ground motions were cut off based on their significant duration, which is defined by the length of time over which the Cumulative Arias Intensity is between $5 \%$ and $95 \%$. Thousands of bi-direction nonlinear dynamic analysis were conducted using OpenSees (PEER, 2011) with the aim of assessing the response of the building portfolio in the most 
critical $x y$-direction of analysis identified by Araújo et al. (2016a). It has been shown by Araújo et al. (2016a) that the ground motion directivity may introduce differences in the loss estimates up to $60 \%$. Considering the most critical direction of analysis will most probably lead to conservative estimates of losses, although such an approach was assumed to be reasonable due to the impracticability of conducting various multi-directional analyses. Structural, nonstructural drift- and acceleration-sensitive and contents fragility functions (i.e. probability of exceeding a number of limit states for a set of intensity measure levels) were derived. The structural damage states proposed by Araújo et al. (2016a) and non-structural and contents damage states defined within the Hazus - MH MR5 framework (FEMA, 2010) were adopted. The fragility functions were convoluted with the consequence model (i.e., loss ratios) defined by Araújo et al. (2016a), which relies on the mean loss ratios proposed within the Hazus - MH MR5 framework and models uncertainty through a multi-variate random generation of loss ratios using Copulas. Vulnerability functions for each building taxonomy proposed by Araujo et al. (2016b) were finally derived. These building taxonomies rely on the buildings' dynamic properties and on multivariate regression and ANOVA analyses (Moore et al., 2009), and account for: (i) the level of wind design - buildings located at altitudes greater than $800 \mathrm{~m}$ were designed to high wind loads (HWD), buildings at altitudes lower that $100 \mathrm{~m}$ were designed to low wind loads (LWD) and buildings at altitudes between $100 \mathrm{~m}$ to $800 \mathrm{~m}$ were assumed to have a medium wind design (MWD); (ii) the building height - buildings with height greater than $5.5 \mathrm{~m}$ were named as High Height $(\mathrm{HH})$, whilst others were named as Low Height (LW); (iii) and the type of base-plate connection - Fixed Base-Plate Connection (FBPC), Nominally Pinned Base Plate Connection (PBPC) and Semi-Rigid Base-Plate Connection (SBPC). For the sake of completeness, it should be referred that the consequence model proposed by Araujo et al. (2016a) also accounts for the fact that property losses may vary with the industrial activity, i.e. industrial property with higher capital demand (e.g., machinery and equipment and value of production equipment) might be hit harder by earthquakes, as well as businesses (i.e. losses to inventory or stocks or losses to production).

Figure 3 presents the mean and 5\%-95\% quantile property vulnerability functions derived based on the methodology proposed Araújo el al. (2016a) for the various building taxonomies and two, i.e. food and pharmaceutical, industrial activities. Three main observations may be readily drawn from the inspection of Figure 3, namely: (i) fixed base-plate (FBPC) buildings designed to withstand high wind loads and with lower height (HWD-LH taxonomy) are more seismically vulnerable. This is due to the fact that this category of buildings is associated to an overall higher lateral stiffness, thus potentially reaching higher levels of acceleration demands, which, as discussed by Araújo et al. (2016a), contribute the most to total property losses (i.e. non-structural acceleration-sensitive components and contents). A remark should be made on the deviations between the vulnerability functions at lower $S_{a}\left(T_{x}\right)$ levels, which are associated to higher probabilities of occurrence, and thus have greater impact on loss quantifications; (ii) similarly to the latter, buildings with nominally pinned base plate (PBPC) connections, which tend to develop higher drift demands in non-structural drift-sensitive components, although with lesser importance in total property loss quantifications, are less seismically vulnerable. In the considered $x y$-direction of analysis, structural damage was found to be mostly governed by lateral braces, permanent drifts and base plate connections, similarly to what was observed by Araújo et al. (2016a) for a single representative building. However, like non-structural drift-sensitive cost ratios, structural repair cost ratios are expected to have lower impact in total building replacement costs when compared to nonstructural acceleration-sensitive components and contents; (iii) industrial activities with 
higher input dependency, i.e. higher equipment and labour intensity and degree of labour specialization (Merz et al., 2013), such as the pharmaceutical industry, are more vulnerable to earthquakes. The vulnerability of these industrial activities is also associated to higher levels of uncertainty, mostly because of the high variability in the value of the fixed assets (e.g. machinery and equipment). Moreover, to highlight the impact of the various building taxonomies on the property loss quantifications, Figure 4 depicts the $95 \%$ quantile of the average loss ratios in 50 years (i.e. ratio between the repair and the replacement costs of the building) obtained for each one of the six building taxonomies proposed by Araújo et al. (2016b) with respect to altitude and height, considering a FBPC support condition and the building to be located in the Lisbon. The seismic hazard was defined on the basis of a Probabilistic Seismic Hazard Analysis (PSHA), carried out using the OpenQuake-engine (Vitor et al., 2014), equally for a time-span of 50 years. Hence, it may be again seen that stiffer buildings are associated to higher property losses, which may reach $16 \%$ of the building replacement cost in hi-tech and heavy industries, and variations up to $50 \%$ may be found between the property losses of taxonomies HWD-LH and LWD-HH. It should be referred that the taxonomy LWD-HH refers to industrial buildings with high height $(\mathrm{HH})$ design to sustain low wind loads.
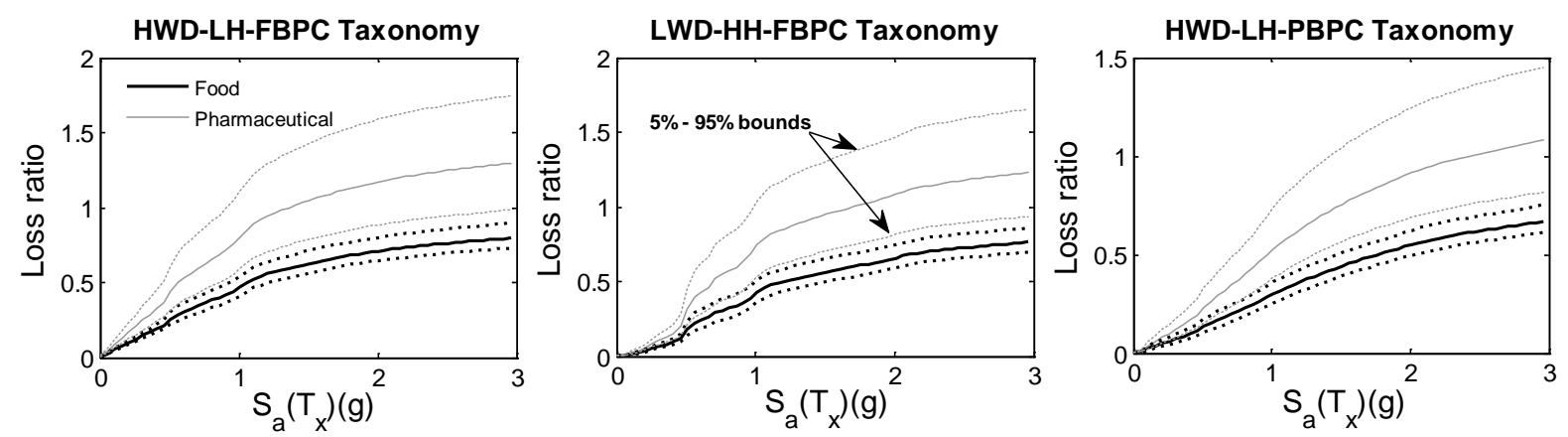

Figure 3: Industrial property vulnerability functions for different building taxonomies and food and pharmaceutical industries: HWD-LH taxonomy with FBPC connection (left), LWD-HH taxonomy with FBPC connection (middle) and HWD-LH taxonomy with PBPC connection (right)

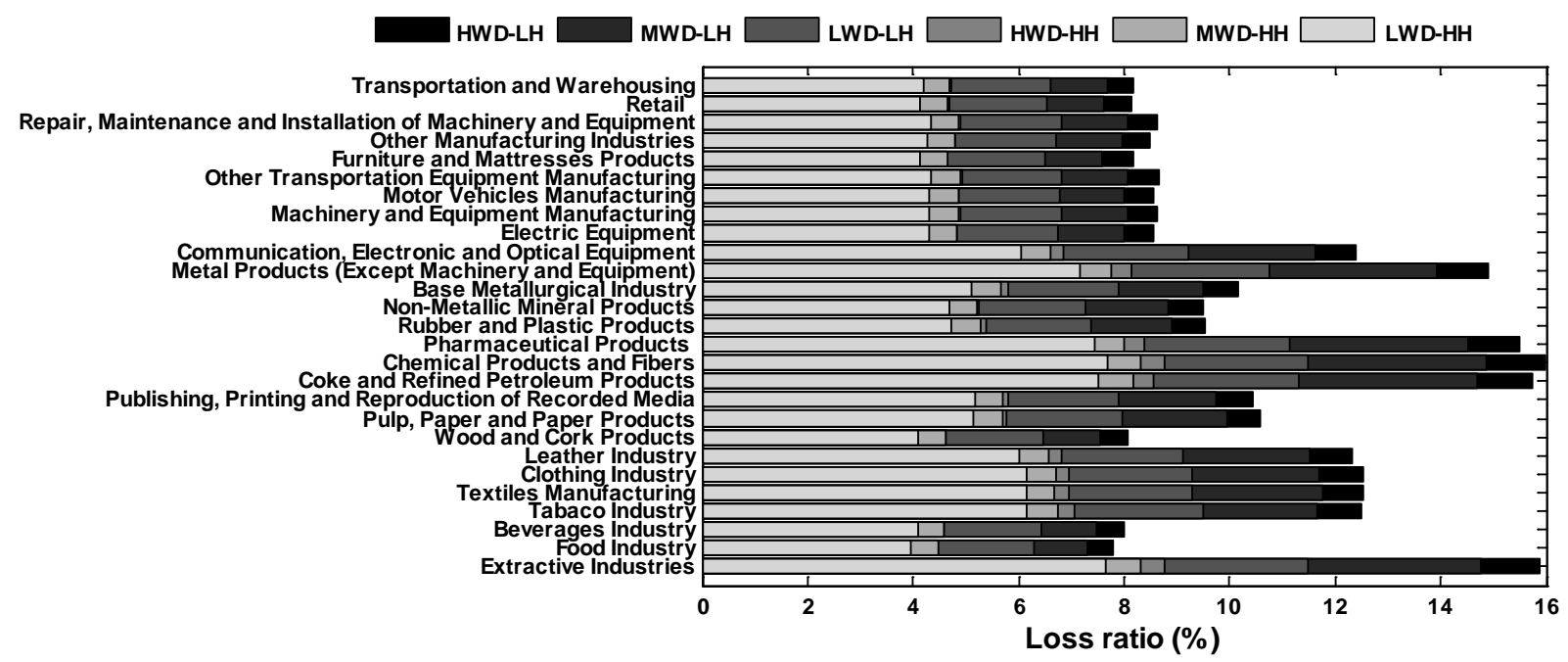

Figure 4: Influence of building taxonomy vulnerabilities with FBPC connections in the $95 \%$ quantile of average property losses in 50 years for the city of Lisbon 


\section{Seismic property losses to the Portuguese industrial steel building stock}

The industrial seismic risk assessment for Mainland Portugal was carried out using the webbased platform developed within the PRISE project. To compute specific property loss maps, the seismic hazard was previously computed and afterwards convoluted with the exposure model developed by Araújo et al. (2016b) and vulnerability model herein briefly presented. Again, the classical PSHA approach was adopted to compute the hazard curves at each site, i.e., a 30 arc sec resolution was considered in agreement with the exposure model developed by Araújo et al. (2016b), for a time span of 50 years. The mean was calculated from this set of hazard curves and a mean hazard map (Figure 5) was computed for a probability of exceedance of $10 \%$ in 50 years (return period of 475 years). Furthermore, building on the OpenQuake Engine PSHA-based risk calculator (Silva et al., 2014), the PRISE project web-based platform convolutes the hazard, exposure and vulnerability models in order to calculate loss exceedance curves for each asset considering each possible path of the logic tree. Hence, based on the set of loss exceedance curves obtained for each asset, mean loss maps for a $10 \%$ probability of exceedance in 50 years were computed, which are presented in Figure 5 . The obtained spatial distribution of industrial property losses in mainland Portugal is coherent with both the spatial distribution of the hazard and the expected geographical distribution of the industrial assets along the Porto-Lisbon corridor. The higher industrial losses are observed along the south-western coastal region of mainland Portugal, being the region of Lisbon and the Tagus Valley expected to be hit harder by an event with a 475 years return period, wherein the direct losses to industrial property may overcome 63 million $€$ within a 30 arc sec grid spacing (approximately $1 \mathrm{~km}$ ). 

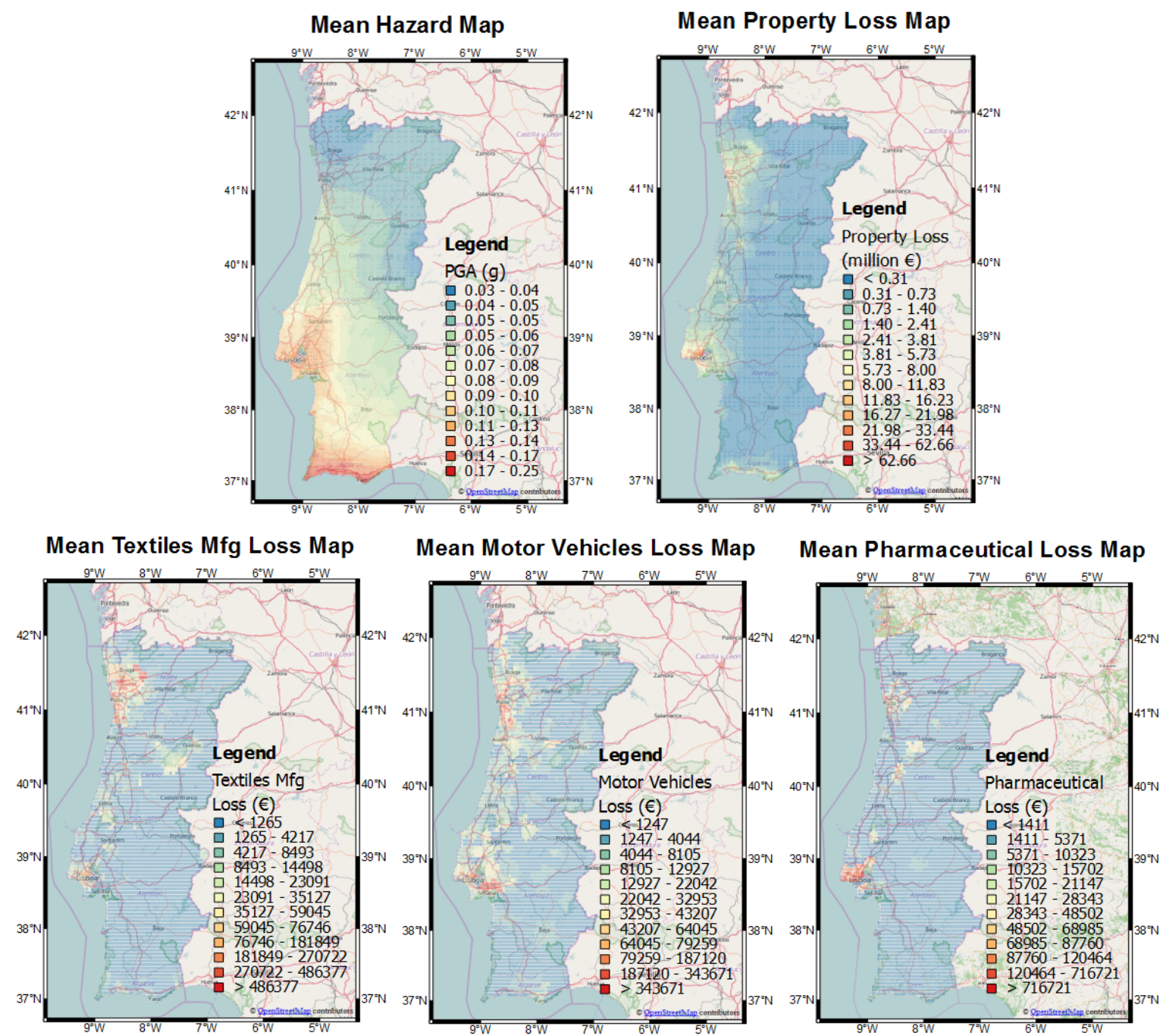

Figure 5: Mean seismic hazard map in peak ground accelerations (PGA) and mean property loss map (upper figures) and mean property losses for different industrial activities, i.e. Textiles Manufacturing, Motor Vehicles Manufacturing and Pharmaceutical Products (lower figures), for a return period of 475 years

Nevertheless, this spatial distribution of industrial losses around the Lisbon and Tagus Valley region and Algarve varies between different industrial activities. By disaggregation the direct industrial property losses, Figure 5 presents the spatial distribution of the mean property losses obtained for the Textile Manufacturing, the Motor Vehicle Manufacturing and the Pharmaceutical Products industries. It may be observed that a significant distribution of losses to the Textile Manufacturing industry is obtained in the Northern region of mainland Portugal, particularly around the Ave Valley region, which is known to be the heart of the Portuguese textile and clothing industry, despite its lower seismic hazard level. Similarly, significant mean property losses to the Motor Vehicle Manufacturing industry were obtained in the Setúbal region (e.g., location of Volkswagen AutoEuropa), south of Porto (e.g., location of Salvador Caetano) and Viseu (e.g., location of the PSA production plant), northeast of Santarém (e.g., location of Mitsubishi-FUSO) and around the Lisbon and Tagus Valley and Porto-Aveiro-Braga regions, wherein about 200 automotive supplier companies are located. In turn, most mean industrial property losses to the Pharmaceutical Products industry are concentrated within the Great Lisbon Metropolitan area. Higher mean aggregated property losses were observed in the food, clothing, metal and non-metallic mineral products industries, being greater or 
around 0.05 billion $€$, and in the retail and transportation and warehousing sectors, reaching up to 1.3 billion $€$. The overall mean aggregated property industrial loss for mainland Portugal has been estimated to be around 2.0 billion $€$, which represents $1.13 \%$ of the Portuguese GDP in 2014. Since the Portuguese industrial sector roughly contributes to $21 \%$ of the national GDP, it may be concluded that a potential $5 \%$ reduction in the country's industrial annual revenue could be expected for a return period of 475 years.

\section{Conclusions}

This paper has investigated the seismic vulnerability and property losses to the Portuguese industrial steel building stock. Based on the inspection of more than 200 blueprints of existing industrial steel buildings collected from Portuguese design offices and steelworks companies, it was herein observed that the majority of the Portuguese industrial building stock is made of steel $(60 \%)$ with $70 \%$ of the buildings having unbraced moment resisting portal frames in the transverse direction and diagonal braces in the longitudinal direction. These buildings typically exhibit 3 to 15 out-of-plane frames spaced by less than $8 \mathrm{~m}$ and a single span. A wide range of synthetic buildings was randomly generated to thoroughly characterize the Portuguese asbuilt industrial steel building stock, being herein concluded that buildings with fixed base-plate connections designed to withstand high wind loads are expected to be more seismically vulnerable as a result of the potentially higher losses to acceleration-sensitive non-structural components, as opposed to buildings with nominally pinned based plate connections designed to sustain low wind loads, which tend to develop higher losses in non-structural driftsensitive components. The structural damage was found to be mostly governed by lateral braces, permanent drifts and base plate connections.

For what concerns the seismic risk assessment, the higher industrial losses were observed to occur along the south-western coastal region of mainland Portugal, being the region of Lisbon and the Tagus Valley the most risk-prone. Still, the spatial distribution of losses was found to significantly vary with industrial activity. Higher mean aggregated property losses were observed in the food, clothing, metal and non-metallic mineral products industries and at the retail, transportation and warehousing sectors. The overall mean aggregated property industrial loss for mainland Portugal was estimated to be around $1.13 \%$ of the Portuguese GDP, representing a $5 \%$ reduction in the country's industrial annual revenue for a return period of 475 years.

\section{References}

Araújo M, Castro JM, Marques M. 2016a. "Seismic losses to property and business activity of industrial buildings. Part 1 - Modelling assumptions and property losses". Earthquake Spectra, in submission.

Araújo M, Castro JM, Marques M. 2016b. "Industrial seismic risk for Mainland Portugal". Natural Hazards, in submission.

Bal El, Crowley H, Pinho R, Gülay FG. 2008. "Detailed assessment of structural characteristics Turkish RC building stock for loss assessment models". Soil Dynamics and Earthquake Engineering, 28, 914-932.

Bradley BA. 2010. "A generalized conditional intensity measure approach and holistic ground motion selection". Earthquake Engineering and Structural Dynamics, 39, 1321-1342.

Burton C, Silva V. 2015. "Assessing Integrated Earthquake Risk in OpenQuake with an Application to Mainland Portugal". Earthquake Spectra, in press. DOI: 10.1193/120814EQS209M. 
Casotto C, Silva V, Crowley H, Nascimbene R, Pinho R. 2015. "Seismic fragility of Italian RC precast industrial structures". Engineering Structures, 94, 122-136.

CEN (2005) "NP ENV 1993-1-1 Eurocode 3: design of steel structures - Part 1-1: general rules and rules for buildings". European Commitee for Strandardization, Brussels, Belgium.

CEN (2010) "NP ENV 1991-1-4 Eurocode 1: actions on structures - Part 1-4: general actions wind actions". European Commitee for Strandardization, Brussels, Belgium.

Clifton C, Bruneau, MacRae G. 2011. "Steel structures damage from the Christchurch earthquake series of 2010 and 2011". Bulletin of the New Zealand Society for Earthquake Engineering, 44, 297-318.

Crowley H, Bommer JJ, Pinho R, Bird H. 2005. "The impact of epistemic uncertainty on an earthquake loss model". Earthquake Engineering and Structural Dynamics, 31, 1653-1685.

Crowley H, Pinho R, Bommer JJ. 2004. "A probabilistic displacement-based vulnerability assessment procedure for earthquake loss estimation". Bulletin of Earthquake Engineering, 2, 173-219.

FEMA. 2010. "Multi-hazard loss estimation methodology. Earthquake Model, HAZUS - MH MR5 Technical Manual". Federal Emergency Management Agency, Mitigation Division. Washington.

Krausmann E, Cruz AM, Affeltranger B. 2010. "The impact of the 12 May 2008 Wenchuan earthquake on industrial facilities". Journal of Loss Prevention in the Process Industries, 23, 242-248.

Lopes M, Pais I, Oliveira S, Sá FM. 2012. "Methodologies for the analysis of the seismic vulnerability of an industrial complex". Proceedings of the 15th World Conference on Earthquake Engineering, Lisbon, Portugal.

Merz M, Hiete M, Comes T, Schultmann F. 2013. "A composite indicator model to access natural disaster risks in industry on a spatial level". Journal of Risk Research, 16, 1077-1099.

Midorikawa M, Nishiyama I, Tada M, Terada T. 2012. "Earthquake and tsunami damage on steel buildings caused by the 2011 Tohoku Japan earthquake". Proceedings of the International Symposium on Engineering Lessons Learned from the 2011 Great East Japan Earthquake, Tokyo, Japan.

Moat AM, Morrison AJT, Wond S. 2000. "Performance of industrial facilities during 1999 earthquakes: implications for risk managers". Proceedings of the Euro Conference on Global Change and Catastrophe Risk Management, Earthquake Risks in Europe. Laxenburg.

Moore JAP, McGabe GP, Craig BA. 2009. "Introduction to the practice of statistics (6 $6^{\text {th }}$ Edition). WH Freeman and Company. New York.

PEER. 2011. "OpenSees: open system for earthquake engineering simulation". Pacific Engineering Research Center. University of California, Berkeley.

REAE (1965) "Regulamento de estruturas de aço para edifícios". Decreto-Lei no 46160. Diário do Governo. Imprensa Nacional, Casa da Moeda, Lisbon, Portugal.

REAE (1986) "Regulamento de estruturas de aço para edifícios". Decreto-Lei no 211/86. Diário da República. Imprensa Nacional, Casa da Moeda, Lisbon, Portugal.

RFCS. 2013. "Prefabricated steel structures for low-rise buildings in seismic areas". Research Fund for Coal and Steel. European Commission. Brussels.

RSA (1983) "Regulamento de segurança e acções para edifícios e pontes". Decreto-Lei no 235/83. Diário da República. Imprensa Nacional, Casa da Moeda, Lisbon, Portugal. 
RSEP (1961) “Regulamento de solicitações em edifícios e pontes”, Decreto-Lei no 44041. Diário do Governo. Imprensa Nacional, Casa da Moeda, Lisbon, Portugal.

Silva V, Crowley H, Pagani M, Modelli D, Pinho R. 2014. "Development of the OpenQuake Engine, the Global Earthquake Model's open-source software for seismic risk assessment". Natural Hazards, 72, 1409-1427.

Silva V, Crowley H, Varum H, Pinho R, Sousa L. 2015a. "Investigation of the characteristics of Portuguese regular moment-frame RC buildings and development of a vulnerability model". Bulletin of Earthquake Engineering, 13, 1455-1490.

Silva V, Crowley H, Varum H, Pinho R. 2015b. "Seismic risk assessment for mainland Portugal". Bulletin of Earthquake Engineering, 13, 429-457.

\section{Acknowledgments}

This work has been performed within the framework of the research project PTDC/ECMEST/3062/2012 'Earthquake loss of the Portuguese building stock' founded by the Foundation of Science and Technology (FCT) of Portugal. The authors would like to express their gratitude to Dr. Joana Neto, Marketing Director of AICEP Global Parques, for providing access to the AICEP Global Find platform database, to Eng.a Alexandra Feliz and Eng.o José Manuel Silva from the steelworks company "O Feliz" and to Eng.- Marco Beleza Vieira from the design office "Projegui" for their availability and support in the survey conducted on the geometrical characteristics of the industrial Portuguese building stock. 